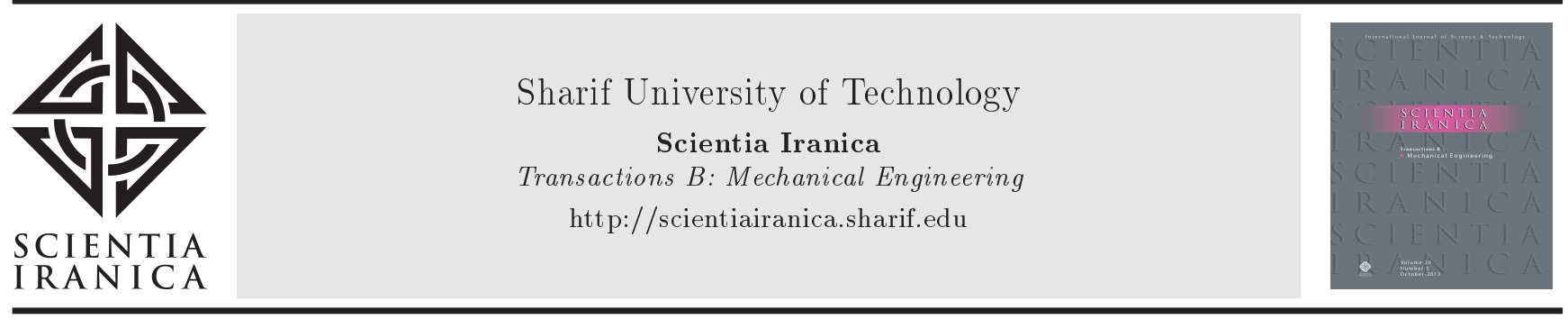

\title{
Experimental evaluation of solar integrated water heater
}

\author{
D.R. Mishra ${ }^{\mathrm{a}, *}$, H. Jain ${ }^{\mathrm{a}}$, N. Kumar ${ }^{\mathrm{a}}$, and M.S. Sodha ${ }^{\mathrm{b}}$ \\ a. Department of Mechanical Engineering, Jaypee University of Engineering and Technology, A.B. Road, Guna-473226, Madhya \\ Pradesh, India. \\ b. Department of Education, University of Lucknow, Lucknow-226007 Uttar Pradesh, India.
}

Received 25 December 2017; received in revised form 5 December 2018; accepted 29 April 2019

\section{KEYWORDS}

Solar water heater;

Heat and mass

transfer;

Modified conventional

bucket;

Power saving;

Cost analysis.

\begin{abstract}
Domestic immersion heaters used for heating cold water are characterized by an electrical resistance heating element, which is encased in a tube and directly placed in it. The most common method for heating cold water is the use of portable immersion rod water heater in an open bucket operating in operator control without a controller unit (thermostat). This paper performs an experimental evaluation of portable modified conventional buckets of 101 capacity. Out of ten portable modified storages, the best three cases are discussed: non-insulated Open Plastic Bucket (OPB), non-insulated plastic bucket top surface covered with a transparent cover (CPB), and insulated plastic bucket closed with a transparent cover (ICPB). Maximum temperatures arising after two hours during OPB, CPB, and ICPB are $29.82 \%, 47.36 \%$, and $21.49 \%$, respectively, compared to the initial temperatures $\left(22.8^{\circ} \mathrm{C}\right)$. At $14: 45$ hour, CPB temperature reaches $35.6{ }^{\circ} \mathrm{C}$, which is $17.88 \%$ and $23.61 \%$ higher than OPB and ICPB units. Due to the application of solar energy in $\mathrm{CPB}$ at $35-50^{\circ} \mathrm{C}$, net saving increased by $12.34 \%, 25.76 \%, 40.73 \%, 57.93 \%$, $76.45 \%$, and $97.18 \%$ from 2017 to 2022 as compared to the saving in 2016 .

(C) 2020 Sharif University of Technology. All rights reserved.
\end{abstract}

\section{Introduction}

The demand for domestic electrical power consumption is increasing day by day due to the population growth in rural and urban areas of developing nations. A significant portion of domestic power is consumed for heating cold water in winter bathing. A detailed review of several solar water heaters was done by Raisul Islam et al. [1]. Several portable and fixed types of solar water heaters are currently available in the market at different initial investment costs; however, their prices are significantly higher than immersion rods. The role of nano-fluid in the solar water heating system

*. Corresponding author.

E-mail address: dm30680@gmail.com (D.R. Mishra)

doi: $10.24200 /$ sci. 2019.50071 .1510 was investigated by Natarajan and Sathish [2]. A parametric study of domestic solar water heaters was conducted by many researchers $[3,4]$. The utilization of an electrical immersion rod in the bucket for the heating of the cold water in the winter session is the most common practice, especially within the rural and urban areas due to the low initial investment cost of the electric immersion rod. The techno-economic water heating system in a bucket through the immersion rod was evaluated by Sodha et al. [5]. They suggested three different methods for the system improvement: (i) insulating lateral and bottom surfaces, (ii) augmentation with the floating cover over water surface, and (iii) augmentation with both. An experimental evaluation of heat flux and heat transfer coefficient using inverse method was done by Farahani et al. [6]. The waterheating system was designed and simulated by Zhang et al. [7]. Jahangiri Mamouri and Bénard [8] performed 
a case study of a new design of an evacuated tubular water heater performance in the climatic condition of Michigan. The life cycle assessment of domestic water hot water cycle was reported by Moore et al. [9]. An evacuated tube collector water heater with a multilayer absorber was investigated by Sobhansarbandi et al. [10]. The average economic performance of solar water heater was studied by Ferrer [11].

As in most of the rural areas of different countries, peoples are still using electric immersion rods for water heating. In case of proper motivation for the partial or full application of solar energy using the proposed methodology, the domestic power consumption can be reduced to a large extent.

\section{Experimental setup}

An real photograph and a schematic view of the portable water heater augmented with the incident solar radiations are shown in Figures 1(a) and 1(b),

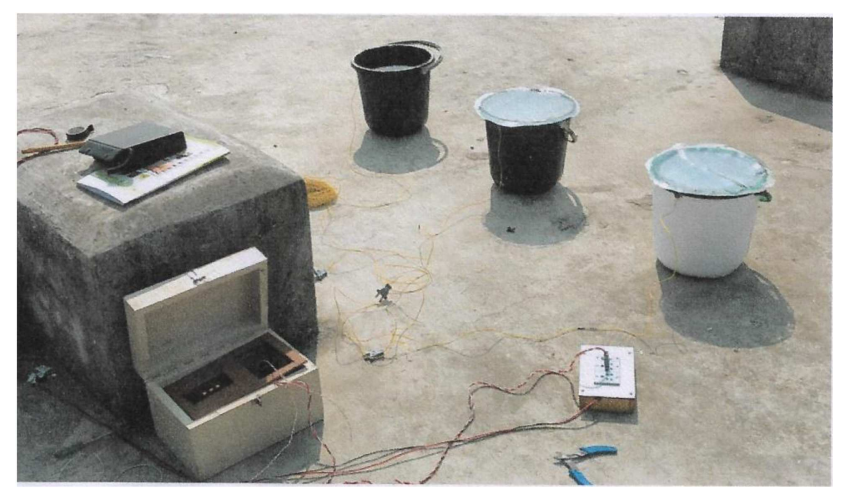

Figure 1a. Actual photographs of OPB, CPB, and ICPB.

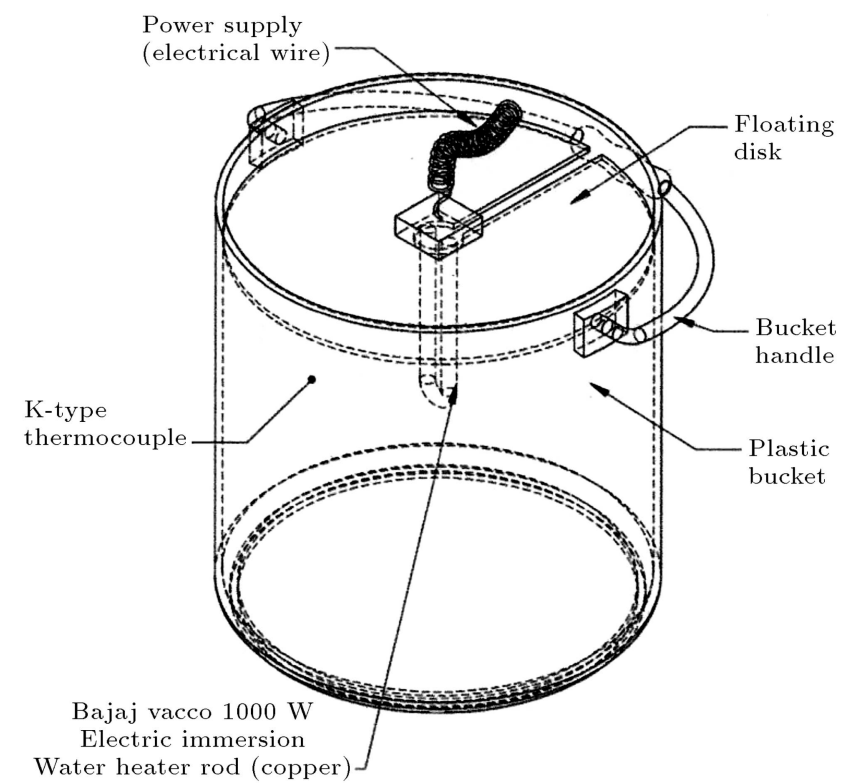

Figure 1b. Schematic representation of CPB along with the immersion rod and floating transparent cover. respectively. The black-colored surface has a better coefficient of absorption than other color surfaces. Hence, the black-colored plastic bucket is characterized by 101 capacities. Three sets of the portable water heater are made of the following: (1) non-insulated, Open Plastic Bucket (OPB), (2) non-insulated plastic bucket, top surface covered with a transparent cover (CPB), and (3) insulated plastic bucket closed with a transparent cover (ICPB). The schematic arrangement of the CPB along with the floating cover and the immersion rod is that the floating cover gives credence to the variation in volumetric mass water within the bucket. OPB, CPB, and ICPB are fed with $10 l$ tab water and have been kept exposed to the incident solar radiation for four hours. K-type thermocouples and MDTI -027 temperature indicators are used for measuring and recording the temperature rise. The following observations are recorded as follows:

- Water temperature rising within OPB, CPB, and ICPB at a 15-min interval;

- Ambient temperature;

- Potential difference (voltage) calculated using a voltmeter;

- Current flowing through the immersion rod using an ammeter.

\section{Mathematical background}

Three different configurations of the water heating in a bucket by an electrical immersion rod are shown.

To perform a mathematical evaluation of the system, the following assumptions are considered:

a. Electric power supply at a constant rate;

b. Cylindrical shape of the bucket;

c. Constant mass of water;

d. Uniform temperature of bucket water;

e. Neglecting evaporative losses, covered bucket with transparent material.

The energy balance mathematical relation for the bucket containing water is given as follows:

$$
M_{w} C_{w} \frac{d T_{w}}{d t}=E_{T}-Q_{s}
$$

where:

$$
\begin{aligned}
& E_{T}=E_{e}+E_{s}, \\
& Q_{n e t \text { loss }}=Q_{c}+Q_{e}+Q_{r}+Q_{s}+Q_{B} .
\end{aligned}
$$

Herein, $E_{T}$ is the total power supplied to the water through solar radiation $\left(E_{s}\right)$ and electrical immersion 
$\operatorname{rod}\left(E_{e}\right)$ in watts, whereas $Q_{\text {net loss }}$ is the energy loss through the conduction, evaporation, and radiation through the top, lateral, and bottom surfaces [12]. Various losses may be given below:

$$
\begin{aligned}
& Q_{c}=h_{c} A_{T}\left(T_{w}-T_{a}\right), \\
& Q_{e}=0.013 h_{c} A_{T}\left(P_{w}-\gamma P_{a}\right), \\
& Q_{r}=h_{r} A_{T}\left(T_{w}-T_{a}\right), \\
& Q_{s}=h_{s} A_{s}\left(T_{w}-T_{a}\right), \\
& Q_{B}=h_{B} A_{B}\left(T_{w}-T_{a}\right) .
\end{aligned}
$$

Heat transfer coefficients are given below [13]:

$$
\begin{aligned}
& h_{c}=5.7+3.8 v, \\
& h_{r}=\frac{\varepsilon_{e f f} \sigma\left[\left(\bar{T}_{w}+273\right)^{4}-\left(\bar{T}_{a}+273\right)^{4}\right]}{\bar{T}_{w}-\bar{T}_{a}},
\end{aligned}
$$

where $\sigma\left(=5.67 \times 10^{-8} \mathrm{~W} / \mathrm{m}^{2} \mathrm{~K}^{2}\right)$ is Stefan's constant, and a bar represents the average (throughout the heating process) of the quantity over it, whereas the effective emissivity of the plate-glazing system can be written as follows:

$$
\begin{aligned}
& \frac{1}{\varepsilon_{e f f}}=\left[\frac{1}{\varepsilon_{w}}+\frac{1}{\varepsilon_{a}}-1\right]^{-1}, \\
& h_{s}=\left[\frac{1}{h_{w s}}+\sum_{j} \frac{2}{K_{j} r_{j}} \ln \left(\frac{r_{j+1}}{r_{j}}\right)+\frac{1}{h_{0}}\right]^{-1}, \\
& h_{B}=\left[\frac{1}{h_{w s}}+\sum_{k} \frac{L_{k}}{K_{k}}\right]^{-1},
\end{aligned}
$$

where $j$ and $k$ denote the numbers of layers of side and bottom of the bucket, respectively.

It has become clear that the evaporative heat transfer coefficient $\left(h_{e}\right)$ has nonlinear dependency on the temperature. The saturated vapor pressure in a narrow range of temperature variations can be represented by linear temperature dependence.

$$
P=R_{1} T+R_{2},
$$

where $R_{1}$ and $R_{2}$ are the constants evaluated using least-squares curve fitting of saturation. The vapor pressure in a longer range of interest can be evaluated through the following relation:

$$
P_{w}=\exp \left(25.317-\frac{5144}{T_{w}+273}\right)
$$

$$
Q_{e}=0.013 h_{c}\left[R_{1}\left(T_{w}-\gamma T_{a}\right)-R_{2}(1-\gamma)\right],
$$

and:

$$
\frac{d T_{w}}{d t}+\alpha T_{w}=\beta
$$

where:

$$
\begin{aligned}
\alpha=[ & {\left[\left(H_{0} A_{T}+h_{s} A_{s}+h_{B} A_{B}\right) / M_{w} C_{w}\right] } \\
\beta= & {\left[E_{T}+\left(H_{1} A_{T}+h_{s} A_{s}+h_{B} A_{B}\right) T_{a}\right.} \\
& \left.-0.013 h_{c} A_{T} R_{2}(1-\gamma)\right] \frac{1}{M_{w} C_{w}}, \\
H_{0}= & \left(h_{c}+h_{r}+0.013 h_{c} R_{1}\right),
\end{aligned}
$$

and:

$$
H_{1}=\left(h_{c}+h_{r}+0.013 h_{c} \gamma R_{2}\right) \text {. }
$$

From Eq. (15), in the initial condition, $T_{w}=T_{w 0}$ and $t=0$, one can get the following:

$$
T_{w}=\frac{\beta}{\alpha}+\left(T_{w 0}-\frac{\beta}{\alpha}\right) \exp (-\alpha t) .
$$

In the cooling mode $(E=0)$ from Eq. (15), one can get:

$$
\frac{d T_{w}}{d t}=-\alpha\left(T_{w}-T_{e f f}\right)
$$

where:

$$
T_{e f f}=\left[T_{a}-\frac{0.013 h_{c} A_{T}(1-\gamma)\left(R_{1} T_{a}+R_{2}\right)}{M_{w} C_{W} \alpha}\right] .
$$

After solving Eq. (17), one can express water temperature:

$$
T_{w}=T_{e f f}+\left(T_{w 0}-T_{e f f}\right) \exp (-\alpha t) .
$$

It is analogous to Newton's law of cooling; it can be observed that $T_{\text {eff }}$ reduces to $T_{a}$ at zero heat loss. The thermal performance of the system can be evaluated using the value of $\alpha$ (loss coefficient) for the typical dataset.

Other influencing parameters can be evaluated through the expressions written below:

i) Time taken to rise the temperature of water from $T_{w 0}$ to $T_{w f}$ can be obtained.

$$
T_{H}=-\frac{1}{\alpha} \ln \left(\frac{T_{w f}-\beta / \alpha}{T_{w 0}-\beta / \alpha}\right) .
$$

ii) The efficiency of utilizing solar and electrical energy $\eta$ can be measured in the following.

$$
\eta=\frac{M_{w} C_{w}\left(T_{w f}-T_{w 0}\right)}{\int_{0}^{t_{h 1}} E_{s} d t+\int_{t_{h 1}}^{t_{h t}} E_{s} d t}
$$




\section{Cost analysis}

The total annual cost of the system can be expressed in response to the corresponding initial investment as follows [14]:

$$
C_{T A}=C_{B} f_{1}+C_{H} f_{2}+C_{E} \int_{0}^{1 Y e a r} E_{T} d t,
$$

where $f_{1}$ and $f_{2}$ are the annuity factors that can be obtained as follows:

$$
\begin{aligned}
& f_{1}=\frac{q^{L} B(q-1)}{q^{L} B-1}, \\
& f_{2}=\frac{q^{L} H(q-1)}{q^{L} H-1},
\end{aligned}
$$

where $q=\left(1+\frac{Z}{100}\right)$.

Annual amount of useful energy $(\mathrm{kWh})$ is obtained below:

$$
Q_{u}=\int_{Y e a r} M_{w} C_{w}\left(T_{w}-T_{w 0}\right) d t .
$$

The cost of $1 \mathrm{kWh}$ of useful energy can be determined as follows:

$$
C_{u}=\frac{C_{T}}{C_{u}} .
$$

\section{Result and discussion}

All the experiments were carried out in January 2017 at Jaypee University of Engineering and Technology, Guna $\left(24.4348^{\circ} \mathrm{N}, 77.1606^{\circ} \mathrm{E}\right)$. Maximum and minimum incident solar radiations on the horizontal surface were recorded as 890 and $640 \mathrm{~W} / \mathrm{m}^{2}$, respectively, during the experimentation. Variation in incident solar radiation was recorded, as shown in Figure 2. At the beginning of the experimentation, the incident solar radiation was recorded at $792 \mathrm{~W} / \mathrm{m}^{2}$, which increased at 13:00 hour by 12.37\%. After 13:00 hour, it started to decline by $28.09 \%$ at $14: 45$ hour during the experimentation.

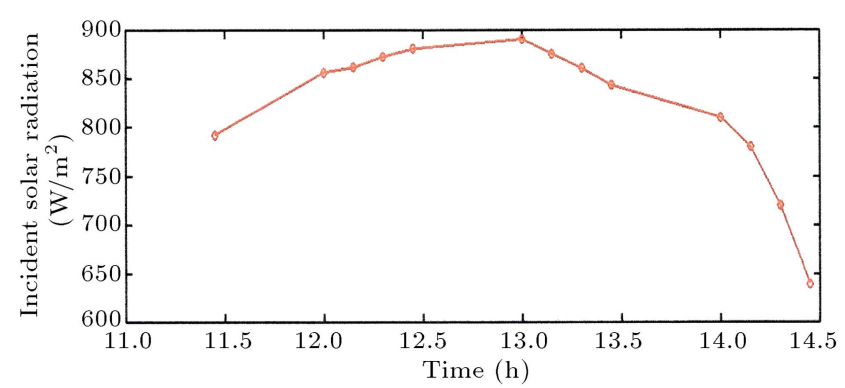

Figure 2. Variation of incident solar radiation with respect to time.
At the beginning of the experimentation, OPC, CPB, and ICPB were filled with the cold water (10 1 each) at a temperature of $22.8^{\circ} \mathrm{C}$, and the results of the experimentation and theoretical evaluation and its variation due to the incident solar radiation as a function of time are shown in Figure 3. Maximum temperatures rising after a two-hour time interval in OPB, CPB, and ICPB are $29.82 \%, 47.36 \%$, and $21.49 \%$, respectively, as compared to the initial temperatures $\left(22.8^{\circ} \mathrm{C}\right)$. Water temperature of $\mathrm{OPB}, \mathrm{CPB}$, and ICPB was determined at its highest value at 14:45 hour during the experimentation, whereas the obtained results of the theoretical models slightly decreased after 14:00 hour due to a reduction in the incident solar radiation.

Water temperature rise in $\mathrm{CPB}$ has maintained its lead throughout the experimentation as compared with the OPB and ICPB, whereas ICPB lags behind as compared with $\mathrm{OPB}$ and $\mathrm{CPB}$ due to the lateral surface insulation. Temperature rise in OPB is more moderate than that in CPB and ICPB.

Temperature increase by water within OPB and CPB due to the Bajaj Vacco (Immersion Water Heater Rod) of $1000 \mathrm{~W}$ capacity.

The temperature rise in both cases was recorded at an interval of two minutes and is shown in Figure 4. Water within the CPB retains more heat as it is covered from the top surface, which is the reason why the temperature rise recorded in $\mathrm{CPB}$ maintains its lead as compared to the OPB throughout the heating process. Due to the presence of the top cover during water heating by means of the immersion rod, the time required to rise unit degree temperature is shorter than that in the OPB and power consumption has reduced in $\mathrm{CPB}$ to a greater extent than that in OPB.

Eight sets $\left(23-50^{\circ} \mathrm{C}, 24-50^{\circ} \mathrm{C}, 28-50^{\circ} \mathrm{C}, 30-50^{\circ} \mathrm{C}\right.$, $34-50^{\circ} \mathrm{C}, 36-50^{\circ} \mathrm{C}, 38-50^{\circ} \mathrm{C}$, and $40-50^{\circ} \mathrm{C}$ ) of the experiment are considered for analyzing the electrical power consumption in OPB and CPB during water heating through an electrical heater. The obtained results of the experimentation are shown in Figure 5 .

Estimated cost saving on the basis of expected

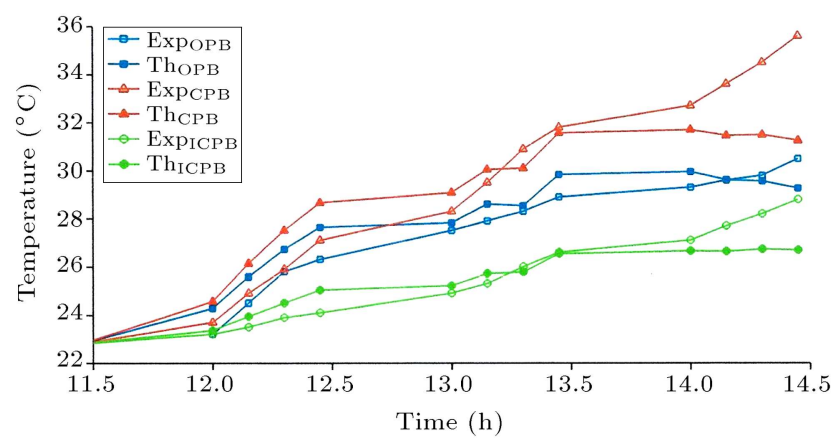

Figure 3. Variation of bucket water temperature due to incident solar radiation with respect to time. 


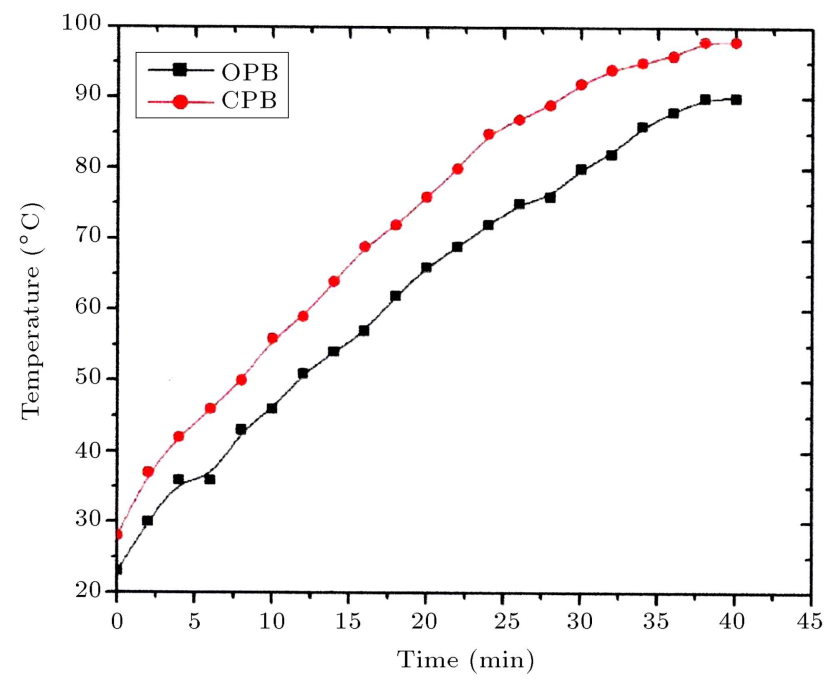

Figure 4. Variation of water temperature in OPB and CPB due to the immersion rod with respect to time.

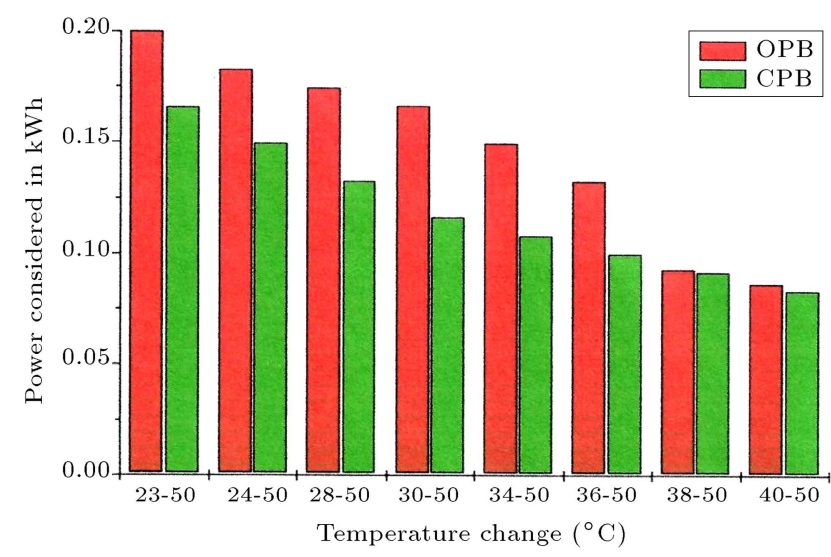

Figure 5. Variation of power consumption with respect to the temperature range.

population growth by World Health Organization (WHO) is shown in Figure 6 due to recorded and expected growth rates in the population of rural and urban areas.

Figure 7 shows the estimated saving from 2016 to 2022 on the basis of the estimated population and $10 \%$ price hike on electricity. Estimated population growth has been recorded at rates of $2.13,3.39,5.74$, $7.86,9.63$, and $11.4 \%$, which are higher than the rates recorded in 2017 to 2022, compared to the population living in 2016. However, net saving resulting from the utilization of solar energy in $\mathrm{CPB}$ in a temperature range of $35-50^{\circ} \mathrm{C}$ increased by $12.34,25.76,40.73$, $57.93,76.45$, and $97.18 \%$ from 2017 to 2022 , compared to saving in 2016.

\section{Conclusions}

Based on experimental theoretical investigations, the following conclusions are drawn:

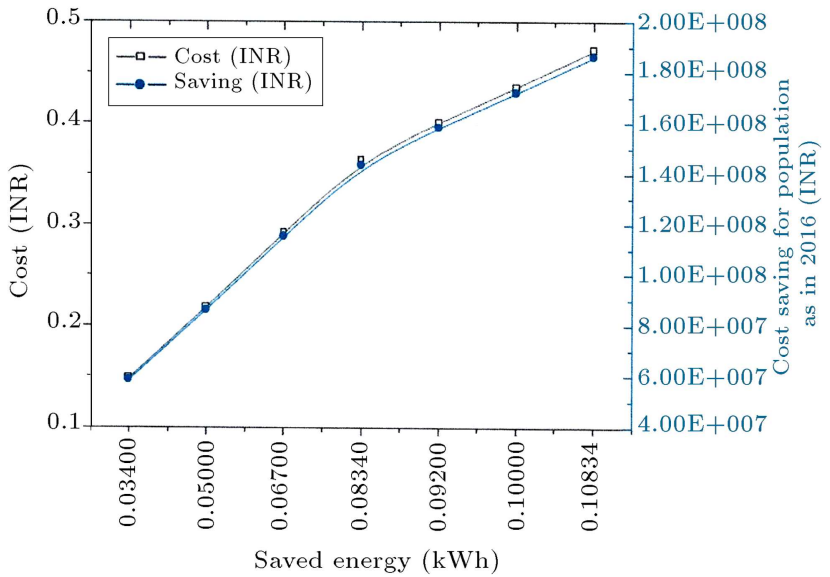

Figure 6. Variation of energy saving and estimated cost as per the domestic rate of Madhya Pradesh (MP) India with respect to saved energy.

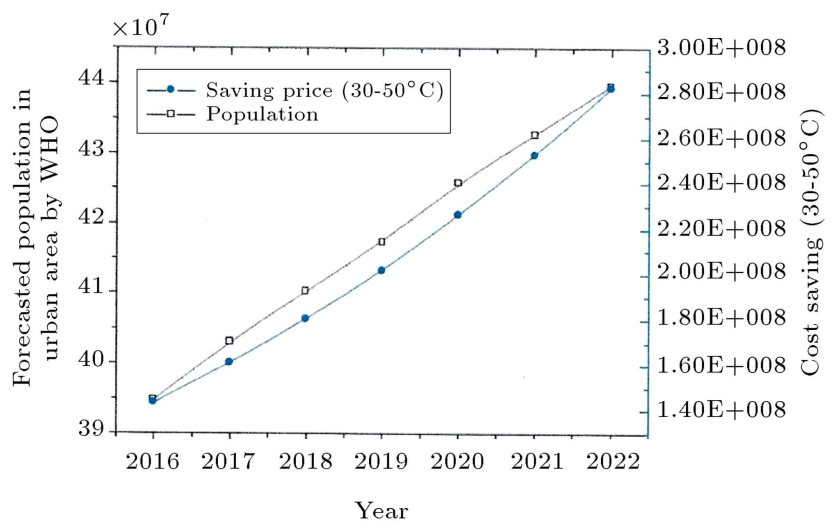

Figure 7. Variation of estimated population growth of urban area by World Health Organization (WHO) and cost saving with respect to the associated year.

- Open bucket water heating using immersion rod is an inefficient process;

- Use of transparent plastic cover mater helps reduce the consumption of electrical power significantly;

- The transparent floating cover can also be a costeffective solution to cost reduction;

- For dry climatic conditions, the electrical heating system operates more uneconomically;

- The application of solar energy for heating of water reduces electric power consumption significantly;

- To reduce heat loss, an immersion rod of higher power rating can be used.

\section{Nomenclature}

$A_{B} \quad$ Bottom surface area of the bucket, $\mathrm{m}^{2}$

$A_{T} \quad$ Top surface area of water, $\mathrm{m}^{2}$

$A_{S} \quad$ Area of sides, $\mathrm{m}^{2}$ 
$C_{B} \quad$ Initial investments in bucket, insulation, and cover, INR

$C_{E} \quad$ Electricity rate, INR/kWh

$C_{H} \quad$ Initial investment cost of an immersion rod, INR

$C_{T} \quad$ Total system annual cost, INR

$C_{u} \quad$ Overall cost of useful energy, INR $/ \mathrm{kWh}$

$C_{w} \quad$ Specific heat of water, $\mathrm{J} / \mathrm{kg}^{\circ} \mathrm{C}$

$C_{T A} \quad$ Total annual cost of the system, INR

$E_{e} \quad$ Electrical energy supplied through immersion rod, W

$E_{s} \quad$ Solar energy received, W

$E_{T} \quad$ Total energy supplied to the bucket through the solar and electrical sources, W

$h_{B} \quad$ Total heat transfer coefficient from the water to the ground through the bottom, $\mathrm{W} / \mathrm{m}^{2 \circ} \mathrm{C}$

$h_{c} \quad$ Convective heat transfer coefficient from top surface / water to ambient air, $\mathrm{W} / \mathrm{m}^{2 \circ} \mathrm{C}$

$h_{r} \quad$ Radiative heat transfer coefficient from cover surface/water to ambient air, $\mathrm{W} / \mathrm{m}^{2 \circ} \mathrm{C}$

$h_{s} \quad$ Total heat transfer coefficient from water to the ambient air through sides, $\mathrm{W} / \mathrm{m}^{2 \circ} \mathrm{C}$

$M_{w} \quad$ Mass of water, $\mathrm{kg}$

$P_{a} \quad$ Partial pressure of saturated water vapor at ambient temperature, $\mathrm{N} / \mathrm{m}^{2}$

$P_{w} \quad$ Partial pressure of saturated water vapor at water temperature, $\mathrm{N} / \mathrm{m}^{2}$

$T_{w} \quad$ Temperature of water, ${ }^{\circ} \mathrm{C}$

$T_{a} \quad$ Ambient temperature, ${ }^{\circ} \mathrm{C}$

$Q_{c} \quad$ Convective heat loss from water/ top surface to the surrounding, W

$Q_{e} \quad$ Evaporative heat loss from water/ top surface to the surrounding, W

$Q_{r} \quad$ Radiative heat loss from water/ top surface to the surrounding, W

$Q_{\text {net loss }} \quad$ Heat loss through lateral surface of bucket, $\mathrm{W}$

$Q_{u} \quad$ Annual useful energy, kWh

$Z \quad$ Percentage rate of interest

$\varepsilon_{e f f} \quad$ Effective emissivity of cover/ water surface

$v \quad$ Velocity of air, $\mathrm{m} / \mathrm{s}$

$\sigma \quad$ Stefan-Boltzmann coefficient (= $5.67 \times 10^{-8} \mathrm{~W} / \mathrm{m}^{2} \mathrm{~K}^{4}$ )

$\gamma \quad$ Relative humidity

\section{References}

1. Raisul Islam, M., Sumathy, K., and Ullah Khan, S. "Solar water heating systems and their market trends", Renewable \& Sustainable Energy Reviews, 17, pp. 1-25 (2013).

2. Natarajan, E. and Sathish, R. "Role of nanofluids in solar water heater", International Journal of Advanced Manufacturing Technology, 8(170), pp. 18761882 (2009).

3. Varghese, J., Samsher, and Manjunath, K. "A parametric study of a concentrating integral storage solar water heater for domestic uses", Applied Thermal Engineering, 111, pp. 734-744 (2017).

4. Aguilar, F.J., Aledo, S., and Quiles, P.V. "Experimental study of the solar photovoltaic contribution for the domestic hot water production with heat pumps in dwellings", Applied Thermal Engineering, 101, pp. 379-389 (2016).

5. Sodha, M.S., Raman, R., Kumar, A., and Goyal, A.K. "Energy conservation in electrical water heating in buckets", International Journal of Energy \& Research, 12, pp. 125-136 (1988).

6. Farahani, S.D., Najafi, A.R., Kowsary, F., and Ashjaee, M. "Experimental estimation heat flux and heat transfer coefficient by using inverse methods", Scientia Iranica, 23, pp. 1777-1786 (2016).

7. Zhang, T., Tan, Y., Zhang, J., and Yu, K. "Design and simulation of a heating system for water puri cation structures in cold rural areas", Scientia Iranica, 22, pp. 2229-2239 (2015).

8. Jahangiri Mamouri, S. and Bénard, A. "New design approach and implementation of solar water heaters: A case study in Michigan", Solar Energy, 162, pp. 165-177 (2018).

9. Moore, A.D., Urmee, T., Bahri, P.A., Rezvani, S., and Baverstock, G.F. "Life cycle assessment of domestic hot water systems in Australia", Renewable Energy, 103, pp. 187-196 (2017).

10. Sobhansarbandi, S., Martinez, P.M., Papadimitratos, A., Zakhidov, A., and Hassanipour, F. "Evacuated tube solar collector with multifunctional absorber layers", Solar Energy, 146, pp. 342-350 (2017).

11. Ferrer, P.A.F. "Average economic performance of solar water heaters for low density dwellings across South Africa", Renewable \& Sustainable Energy Reviews, 76, pp. 507-515 (2017).

12. Tiwari, G.N., Solar Energy: Fundamentals, Design, Modelling and Applications, Alpha Science International Ltd. (2002).

13. McAdams, W.C., Heat Transmission, 3rd Ed., McGraw-Hill, new York (1954). 
14. Garg, H.P. "Technoeconomics of solar forced flow hybrid hot water system", in: Solar Water Heating Systems, D. Redel Publishing Company, Holland, pp. 385-402 (1985).

\section{Biographies}

Dhananjay R. Mishra is an Assistant Professor Senior (SG) at the Department of Mechanical Engineering at Jaypee University of Engineering \& Technology, Guna. He received his PhD in Mechanical Engineering from National Institute of Technology Raipur, India in 2016. He has published more than 50 research papers in reputable peer-reviewed national and international journals. He has supervised four PhD students from Jaypee University of Engineering \& Technology and National Institute of Technology Raipur. He is an Editor in 'International Journal of Thermodynamics \& Catalysis', an Associate Editor of International 'Journal of Applied Research', and an editorial board member of nine other peer-reviewed international Journals. He has an affiliation with the Suprabha Industries Ltd., Lucknow, as an Assistant Production Manager during 2002-2004 as a lecturer at the Mechanical Engineering Department, Rungta College of Engineering and Technology, Bhilai, C.G. During Sept. 2005 to March 2006, he was a Lecturer at the Mechanical Engineering Department, Shri Shankaracharya College of Engineering and Technology, Bhilai, C.G. (During March 2006 to July 2007) as an Assistant Professor at the Department of Mechanical Engineering at Disha Institute of Management \& Technology. He has also been the incumbent Academic Administrator (July 2007 to July 2012). Since July 2012, he has been an Assistant Professor (SG) at the Mechanical Engineering Department, JUET, Guna (M.P.). He has established State Level Energy Park at DIMAT funded by MNRE through Nodal agency CREDA. He has also completed a research project titled "determination of the parameters affecting heat transfer between the ground and fully or partially underground structures" sponsored by Chhattisgarh Council of Science and Technology at Disha Institute of Management \& Technology, Chhattisgarh.

Hrishi Jain is pursuing his MTech in Ocean Technology from IIT Madras. He was born on September 21, 1994 at the Tikamgarh district of M.P. India and has completed his higher secondary school from Hope Academy Tikamgarh and secured 80\%. He completed his BTech in Mechanical Engineering at Jaypee University of Engineering \& Technology in 2017 and worked as a Design Engineer for the ATV (All-Terrain Vehicle) in college team Ardent Clan and ATV at Gautam Buddha University Noida in Off Road Challenge competition. He is currently pursuing his MTech in Ocean Technology at IIT Madras and completed his thesis titled "development of thermally rechargeable ARGO float using ocean thermal gradient" with National Institute of Ocean Technology (NIOT) Chennai. He has an affiliation with the startup Terero Mobility mentored by Lockheed Martin at IIT Madras a Finite Element Analysis (FEA) lead. He has published two international research articles in peerreviewed international conferences/journals.

Nishant Kumar works with Shrota Enterprises Pvt. Ltd. as a Production Planning \& Control (PPC) officer. He was born on November 11, 1993 in the Patna district of Bihar India. He has completed his higher secondary school from R.K.S College, West Champaran and received his BTech degree in Mechanical Engineering from Jaypee University of Engineering \& Technology in 2017. He has worked as a Fabrication Engineer and Steering Incharge for the ATV (AllTerrain Vehicle) in college team Ardent Clan and raced our ATV at Gautam Buddha University Noida in Off Road Challenge competition and published two international research articles in peer-reviewed international conferences/journals.

Mahendra Singh Sodha is a visiting Professor at the Department of Education and Physics, Lucknow (UP). He was born in Ajmer district of Rajasthan on February 8, 1932. He pursued his higher education at the University of Allahabad. After receiving his D Phil in "Theory of Spectroscopy Instruments" in 1955, he joined Defense Science Laboratory in Delhi for a short period of time. From 1956 to 1964, he worked in Canada and the USA at different capacities. He was appointed a Professor at the Department of Physics at the Indian Institute of Technology Delhi, New Delhi, 1964. Professor Sodha has made outstanding contributions in the areas of energy, plasma, solid state physics, optics, combustion, and ballistics. He has published more than 500 research papers in reputable national and international journals. He has to his credit 13 books and 12 reviews. He has also supervised more than $65 \mathrm{PhD}$ students from IIT Delhi and other Universities. Professor Sodha was awarded the prestigious S.S. Bhatnagar award in 1974, Hari Om Ashram Prerit Shri S.S. Bhatnagar award in 1978, and Padmashri award in 2003 for his outstanding contributions in science and engineering. $\mathrm{He}$ is a fellow in many professional bodies including Indian National Science Academy and National Academy of Science, India. He has been a member of the editorial board of national and international journals. Professor Sodha served IIT Delhi at many capacities including Head of the Department of Physics (1966-1968); Head of the Centre for Energy Studies (1978-1982); Dean (Science, Students, PG Studies) (1970-76), and Deputy 
Director (1982-1985). He has also served as the ViceChancellor of Lucknow University, Lucknow (1992-95) and Barkatullah University, Bhopal (1998-2000). He has played an active role in the promotion of higher education in India. He has been instrumental in setting up the Centre for Energy Studies at IIT Delhi and Faculty of Engineering Sciences at Indore. He is currently a Ramanna Fellow and a Visiting Professor at the Department of Education and Physics, Lucknow (UP). 